\title{
A RELAÇÃO ENTRE OS SABERES DA GEOGRAFIA ESCOLAR E DA ACADÊMICA: IMPACTOS NA FORMAÇÃO DO PROFESSOR
}

\author{
The relation between the knowledge of school geography and academic geography: impacts \\ in teacher training
}

\author{
Cláudia Simone Lemos Almeida* \\ Antonio Carlos Pinheiro** \\ * Acadêmica do PPG em Geografia da UFPB - csimone la@hotmail.com. \\ **Docente do PPG em Geografia da UFPB - antoniocarlospinheiro@uol.com.br.
}

Recebido em 08/08/2018. Aceito para publicação em 25/08/2018.

Versão online publicada em 20/11/2018 (http://seer.ufrgs.br/paraonde)

\begin{abstract}
Resumo: A discussão sobre a formação inicial e saberes docentes têm se tornado objetos de reflexões por parte das produções textuais e também de políticas públicas nas últimas décadas. Mediante a isso, o presente trabalho tem como objetivo compreender a relação entre os conhecimentos da Geografia escolar e os conhecimentos da Geografia acadêmica e suas influências na formação do professor. Utilizamos como abordagem metodológica para a realização do trabalho, a pesquisa qualitativa baseada na história de vida, nas entrevistas e observações dos sujeitos. Ouvir esses professores e observar suas práticas é oportunizar que os mesmos participem da pesquisa como sujeitos centrais, possibilitando que reflitam sobre suas ações nas aulas de Geografia. A pesquisa faz parte da dissertação de mestrado que se encontra em andamento, mas já apresenta algumas considerações a respeito do tema.
\end{abstract}

Palavras-chave: Formação docente; Geografia acadêmica; Geografia escolar.

\begin{abstract}
The discussion about pre-service teacher education and teacher knowledges have become an object of study by the science and also a target of public policies over the last decades. Therefore, this study aims to understand the influence of the knowledge of school and academic Geography in the pre-service teacher education as well as in their practice in the classroom. We used a qualitative research based on the life history, interviews and observation of the individuals as a methodological approach for this research. Listening to these teachers and observing their practices is to enable them to participate in the research as central subjects, allowing them to reflect on their actions in Geography classes. The research is part of a master's degree in progress, but already presents some considerations on the subject.
\end{abstract}

Key-words: Teacher training; Academic Geography; School Geography.

\section{1 - Introdução}

A formação de qualquer profissional é permeada por diversos aspectos relacionados à criação desse indivíduo, sua vivência escolar e universitária, bem como as experiências adquiridas ao longo de sua carreira. Com a formação docente ocorre o mesmo, durante todo seu processo formativo, o professor vai adquirindo ao longo do tempo, saberes que surgem desde a sua criação familiar, passando por sua vivência na escola como aluno, se estendendo pela sua formação inicial e contínua, dentro e fora da universidade e por meio da sua práxis educacional dentro da escola.

Essa temática relacionada aos saberes e a formação dos professores vem ganhando espaço nas pesquisas em educação. De acordo com Pimenta (1997), Nóvoa (2007) e Tardif (2014) ela começa na Europa desde o início da década de 1990, e se estende por vários países latino-americanos, especialmente no Brasil.

Tardif (2014) relata que os trabalhos sobre essa temática dos saberes eram referentes a profissionalização do ensino, mas que ultimamente vem abrangendo outras questões como o trabalho e a formação docente, o pensamento e a história de vida dos professores, entre outras.

Compreender sobre esses diversos saberes na formação docente é importante para 
entendermos como ocorreu, e vem ocorrendo a formação desse profissional, como utiliza esses saberes no cotidiano escolar em relação à disciplina ministrada e sua socialização com os alunos. Tardif $(2014$, p. 228) afirma que "os professores de profissão possuem saberes específicos que são mobilizados, utilizados e produzidos por eles no âmbito de suas tarefas cotidianas".

Mediante os argumentos supracitados percebemos que é relevante para nossa pesquisa levar em consideração os conhecimentos produzidos pelos professores que atuam na Educação Básica, e não apenas vê-los como meros reprodutores dos conhecimentos produzidos pelos intelectuais. É preciso que haja uma parceria maior entre essas classes na produção de pesquisas relacionadas à educação, principalmente, formação de professores. Nóvoa (2007) propõe "a necessidade de uma formação de professores construída dentro da profissão, [...] isto é, baseada numa combinação complexa de contributos científicos, pedagógicos e técnicos, mas que tem como âncora os próprios professores mais experientes e reconhecidos".

Considerando o exposto anteriormente sobre os saberes e a formação docente, esta pesquisa tem como objetivo geral compreender a relação entre os conhecimentos da Geografia escolar e os conhecimentos da Geografia acadêmica e suas influências na formação do professor. Buscamos com isto entender como os professores da Educação Básica utilizam e mobilizam os conhecimentos adquiridos ao longo de sua formação em Geografia, principalmente relacionados aos conteúdos geográficos, na sua práxis em sala de aula. E também analisar se existe um distanciamento entre esses conhecimentos por meio da visão dos docentes acerca de sua formação.

A discussão sobre a interação entre os saberes da Geografia acadêmica e os saberes da Geografia escolar é um tema relevante para a compreensão da formação inicial docente e também saber como esses saberes são mobilizados na sala de aula. É mediante os conhecimentos adquiridos por meio de um currículo que norteia os cursos de Licenciatura que muitos professores pensam e planejam sua forma de ministrar os conteúdos na Educação Básica.

Nosso trabalho é embasado na abordagem qualitativa de pesquisa em educação, com enfoque na história de vida dos professores de duas escolas estaduais de Ensino Médio localizadas em Limoeiro do Norte-CE: a Escola de Ensino Médio Lauro Rebouças de Oliveira e a Escola de Ensino Médio Arsênio Ferreira Maia. Por meio de entrevistas semiestruturadas com esses docentes, buscamos entender como ocorreu o processo de formação inicial e a sua influencia na práxis cotidiana na sala de aula.

Além dos professores da Educação Básica, também faremos entrevistas com os professores formadores da Faculdade de Filosofia Dom Aureliano Matos- FAFIDAM câmpus da Universidade Estadual do Ceará-UECE localizada também em Limoeiro do Norte-CE e, responsável pela formação dos professores que atuam nas escolas pesquisadas.

\section{2 - Os diversos saberes na formação do professor}

A formação profissional docente apresenta um conjunto de saberes que vão sendo adquiridos ao longo do tempo, e também que estão entrelaçados com o contexto histórico e do trabalho em que estão envolvidos. Nessa perspectiva Tardif (2014, p. 11) afirma que: “[...] o saber dos professores é o saber deles e está relacionado com a pessoa e a identidade deles, com sua experiência de vida e com a sua história profissional, com as suas relações com os alunos em sala de aula e com outros atores escolares na escola, etc".

Nesse sentido, percebemos que esses saberes são construídos na relação, principalmente, com outros sujeitos da escola, sobretudo com os alunos. Tardif (2014) afirma que os saberes dos professores são "saberes sociais". Ao longo da sua carreira profissional, o professor tem que lidar com uma quantidade enorme de sujeitos com visões de mundo diferentes. E nessa convivência diária, acontece uma troca de saberes não só a respeito de conteúdos, mas também de experiências de vida.

Nessa perspectiva, percebemos que existe uma diversidade grande de saberes, e que são provenientes de várias fontes. Parafraseando Tardif (2014) os saberes docentes são plurais, heterogêneos e temporais, vindos de fontes diversas e de natureza diferentes. "Esses saberes são os saberes disciplinares, curriculares, profissionais (incluindo os das ciências da educação e da

Para0nde!?, Porto Alegre, v.10, n.2, p.96-102, 2018. Edição Especial com artigos publicados originalmente na XII ENANPEGE http://seer.ufrgs.br/paraonde 
pedagogia) e experienciais" (TARDIF, 2014, p. 33).

Tardif (2014) faz um aparato geral da origem desses saberes. Os saberes profissionais vêm das instituições de formação de professores, e também de reflexões racionais e normativas que são feitas por pesquisadores para a prática educativa, e utilizadas na construção de documentos. Temos os saberes disciplinares que são integrados à formação docente por meio das diversas disciplinas contidas nas matrizes curriculares dos cursos.

0 autor supracitado nos fala também sobre os saberes curriculares que se apresentam como discursos, objetivos, conteúdos e métodos considerados importantes, e que servem de modelos para serem aprendidos e aplicados pelos professores. E por fim os saberes experienciais, que são aqueles desenvolvidos pelos professores no exercício de suas funções na escola.

Percebemos que esses saberes são oriundos, principalmente, das instituições formativas. São formados por especialistas em educação, mas que às vezes desconhecem o contexto de trabalho em que os professores da Educação Básica estão inseridos. É necessário conhecermos como os professores lidam com esses saberes na sua prática educativa. Quais saberes eles utilizam em seu cotidiano? A formação docente está conseguindo articular esses saberes na formação do professor de Geografia? Tardif (2014, p. 39) afirma que em relação aos saberes: “[...] o professor é alguém que deve conhecer sua matéria, sua disciplina e seu programa, além de possuir certos conhecimentos relativos às ciências da educação e à pedagogia e desenvolver um saber prático baseado em sua experiência cotidiana com os alunos".

O saber docente de acordo com Tardif (2014) e Zeichner (1998) ainda é desvalorizado pelos especialistas em educação, o que ocasiona a separação do que é produzido na universidade, e em outras instituições responsáveis pela educação, do que é produzido pelos professores da escola. Tardif (2014, p. 41) declara que:

A relação que os professores estabelecem com os saberes da formação profissional se manifesta como uma relação de exterioridade: as universidades e os formadores universitários assumem as tarefas de produção e de legitimação dos saberes científicos e pedagógicos, ao passo que os professores competem apropriar-se desses saberes, no decorrer de sua formação, como normas e elementos de sua competência profissional, competência essa sancionada pela universidade e pelo Estado. Os saberes científicos e pedagógicos integrados á formação dos professores precedem e dominam a prática da profissão, mas não provém dela.

Essa constatação nos faz refletir sobre a desvalorização do professor da Educação Básica por parte dos pesquisadores universitários e também do Estado. Zeichner (1998, p. 217) afirma que "os professores não vêem muito valor nas pesquisas dos acadêmicos e os acadêmicos não vêem valor nas pesquisas dos professores- os mundos dos pesquisadores acadêmicos e dos pesquisadoresprofessores raramente se cruzam".

Sabemos que é preciso ouvir o que os professores têm a dizer a respeito de sua formação profissional. A opinião desses sujeitos sobre os saberes disciplinares, curriculares e pedagógicos é relevante para que se tenha uma formação docente que aproxime mais os conteúdos da ciência geográfica ministrada na universidade da disciplina de Geografia ministrada na escola.

Nessa perspectiva vamos trabalhar com os saberes disciplinares, pedagógicos e também experiências dos professores da Educação Básica, buscando compreender como eles adquiriram esses saberes durante sua formação profissional, e como os utilizam para ministrar os conteúdos de Geografia na escola.

\section{3 - As mudanças curriculares e a formação docente}

Historicamente a temática referente a formação docente tem ganhado espaço nas discussões no âmbito educacional. Nas últimas décadas esses debates giram em torno de políticas voltadas para qualidade do profissional docente e também atender as demandas de uma escola cada vez mais

ParaOnde!?, Porto Alegre, v.10, n.2, p.96-102, 2018. Edição Especial com artigos publicados originalmente na XII ENANPEGE http://seer.ufrgs.br/paraonde 
complexa e constituída por uma diversidade de sujeitos. Cacete $(2013$, p. 56) afirma que: "A escola é, portanto, sempre lugar de possibilidades múltiplas configurando um território educativo permeado por contradições e desafios onde os professores contribuem com seus saberes, sua experiência, seus valores na complexa tarefa de melhorar a qualidade da educação [...]".

Nesse sentido de contribuir para a formação docente, e também na busca de incorporar as medidas, ditas neoliberais, impostas por instituições financeiras, dentre elas, o Banco Mundial, são iniciadas a partir da década de 1990, as reformulações educacionais nos sistemas de ensino brasileiro. As reformulações educacionais, segundo Cavalcanti (2012, p. 14) buscava

[...] a melhoria da educação escolar para cumprir exigências de formação básica em uma sociedade caracterizada por significativos avanços científicos e tecnológico, por um mercado global competitivo e por um novo padrão produtivo, várias ações, programas e políticas foram implementados norteando o projeto educativo do país.

Nesse contexto, foram criadas algumas políticas públicas, por exemplo: a Lei 9394/96 a Lei de Diretrizes e Bases da Educação Nacional (LDB); os Parâmetros Curriculares Nacionais (PCN) para o ensino fundamental e médio. Todavia discutiremos o Parecer CNE/CP 9/2001 (BRASIL, 2001a) que institui as Diretrizes Curriculares Nacionais para a Formação de Professores da Educação Básica, em nível superior, curso de licenciatura, de graduação plena; o Parecer 21/2001 (BRASIL, 2001b) que estabelece a duração e a carga horária dos cursos de licenciatura; o Parecer CNE/CP 02/2015 (BRASIL, 2015) que institui as Diretrizes Curriculares Nacionais para a formação inicial e continuada em nível superior de profissionais do magistério para a Educação Básica.

Atemo-nos aqui para as políticas voltadas para a modificação dos currículos das licenciaturas. O Parecer CNE/ CP 9/2001(BRASIL, 2001a) que propôs a criação das DCN para a formação de professores da Educação Básica, em nível superior, curso de licenciatura, de graduação plena, tem como principal objetivo, segundo Leão (2013, p. 16): "Estabelecer novos parâmetros para a formação de professores no Brasil e garantir para as licenciaturas uma nova legislação que lhes dê "terminalidade e integralidade própria em relação ao bacharelado, constituindo-se em um projeto especifico".

Nessa perspectiva, de autonomia dos cursos de licenciatura, o Parecer 09/2001(BRASIL, 2001a) destaca questões que precisam ser revistos alguns elementos para uma melhor formação do profissional docente, dentre eles podemos citar: aproximação entre as universidades e os sistemas de ensino da Educação Básica, desenvolvendo projetos compartilhados; a unidade entre teoria e prática dentro matriz curricular, a dicotomia entre licenciatura e bacharelado.

Visando essa aproximação entre universidade e escola, o Parecer 21/2001 (BRASIL, 2001b) e o Parecer 02/2015 (BRASIL, 2015) estabeleceram algumas mudanças na carga horária dos cursos de licenciatura. De acordo com os pareceres, os cursos de licenciatura contariam agora com uma carga horária de 3.200 horas; com 400 horas de prática como componente curricular, vivenciadas ao longo do curso; com 400 horas de estágio curricular supervisionado a partir do início da segunda metade do curso, dentre outras mudanças.

No centro dessas reformulações, foi criado o Parecer CNE/CES 492/2001(BRASIL, 2001) que institui as Diretrizes Curriculares Nacionais dos cursos de Ciências Humanas, onde está inserido o curso de Geografia. O Artigo 1ำ do Parecer institui que as DCN do curso de Geografia deverão orientar a formulação do projeto pedagógico do referido curso. Já o Artigo 2o do mesmo Parecer institui que o projeto pedagógico de formação acadêmica e profissional a ser oferecido pelo curso de Geografia deverá explicitar:

0 perfil dos formandos nas modalidades bacharelado, licenciatura e profissionalizante; as competências e habilidades; a estrutura do curso, os conteúdos básicos e complementares e respectivos núcleos; os conteúdos definidos para a Educação Básica, no caso das licenciaturas; o formato dos estágios; as características das atividades complementares e as formas de avaliação (BRASIL, 2001).

Apesar de algumas Instituições de Ensino Superior já terem feito seus projetos pedagógicos

Para0nde!?, Porto Alegre, v.10, n.2, p.96-102, 2018. Edição Especial com artigos publicados originalmente na XII ENANPEGE http://seer.ufrgs.br/paraonde 
de acordo com as DCN, "algumas licenciaturas não conquistaram terminalidades e integralidades próprias" (LEÃO, 2013, p. 16). Esse fato ocorre devido aos seguintes aspectos frisados pelo mesmo autor que seriam:

As políticas de formação de professores e o papel da matriz curricular dos cursos de licenciatura em Geografia, a falta de identificação do professor em relação as questões pedagógicas; a lacuna entre o ensino superior e Escola Básica e o papel das práticas na formação do futuro professor (LEÃo, 2013, p. 16-17).

Todos esses pontos citados acima demonstram as dificuldades pelas quais passam a formação docente nos cursos de licenciatura. Muitos ainda se configuram como extensão dos cursos de bacharelado, como é o caso do curso de licenciatura em Geografia.

Considerando a importância da formação do profissional docente para a Educação Básica, foi elaborada por meio do Parecer CNE/CP 02/2015, as Diretrizes Curriculares Nacionais para a formação inicial e continuada dos profissionais do magistério da Educação Básica. De acordo com o Artigo 1ำ do primeiro capítulo desse Parecer, o objetivo das DCN é: "Definir princípios, fundamentos, dinâmica formativa e procedimentos a serem observados nas políticas, na gestão e nos programas e cursos de formação, bem como no planejamento, nos processos de avaliação e de regulação das instituições de educação que as ofertam" (BRASIL, 2015, p. 2).

Nesse intuito, ela apresenta na sua constituição alguns elementos referentes as DCN anteriores, a exemplo da relação teoria e prática nas matrizes curriculares, a aproximação entre universidade e escola, como ponto relevante na formação inicial e continuada do professor, entre outros. Uma questão que merece destaque dentro desse documento é a preocupação com a valorização do professor, durante todo o texto, essa questão é levantada, visto que, é necessário levar em consideração as condições salariais e de trabalho desse profissional. Diante dessa desvalorização, Gatti (2000, p. 1) ressalta que:

0 mais grave é que a profissão de professor tem se mostrado cada vez menos atraente para camadas importantes de nossa juventude, tanto pelas condições de ensino dos cursos em si como pelas condições em que seu exercício se dá, passando pelos aspectos salariais e de prestígio social. Os pesquisadores que têm tratado da questão, não de hoje, sentem-se como verdadeiro "João Batista" pregando no deserto.

Na verdade, a profissão professor não tem se tornado menos atraente apenas para os jovens de classes mais elevadas, mas também para os jovens de classes mais baixa, pois estes também não querem ser submetidos as condições de trabalho do profissional docente, tendo que lhe dar com classes numerosas, com locais de trabalho inadequados e ainda com uma carga horária, que não lhe permite refletir sobre sua prática.

Mediante a criação dessas políticas educacionais surgem algumas questões que precisam ser debatidas. Uma delas é a participação, principalmente, dos professores da Educação Básica na construção dessas políticas. Outra questão é se essas políticas estão sendo postas em prática ou se apenas estão no papel. Outro ponto relevante é que muitos cursos de licenciatura fizeram seus projetos de acordo com esses documentos, mas na prática essas mudanças não acontecem efetivamente. Noutras palavras, os projetos pedagógicos dos cursos trazem no seu relatório uma relação intrínseca ente teoria e prática, mas essa relação não acontece efetivamente quando as disciplinas são ministradas.

\section{4 - Dialogando com os professores da Educação Básica}

Pensando na relação entre os conhecimentos da Geografia escolar e da Geografia acadêmica fizemos até o momento da pesquisa entrevistas semiestruturadas com seis professores pertencentes às escolas mencionadas acima, onde perguntamos a esses docentes, se eles percebiam um distanciamento entre os conteúdos de Geografia ministrados na universidade no período em que fizeram o curso, para os conteúdos de Geografia que ministravam em suas aulas na Educação Básica.

Dos seis professores entrevistados, cinco disseram que sente esse distanciamento entre os

Para0nde!?, Porto Alegre, v.10, n.2, p.96-102, 2018. Edição Especial com artigos publicados originalmente na XII ENANPEGE http://seer.ufrgs.br/paraonde 
conteúdos que são vistos na universidade e os conteúdos ministrados na escola, e que isso dificultou o trabalho deles na escola. Já um professor relatou que na verdade não percebe esse distanciamento, mas sim que ele ver uma diferença na forma como os conteúdos geográficos são abordados tanto na universidade como na escola.

Os professores ressaltaram também que durante seus processos formativos sentiram falta de uma interação da universidade com a escola. E que essa interação acontecia muitas vezes apenas nas disciplinas de Estágio Supervisionado, ou seja, próximo ao término do curso. A falta dessa relação entre essas instituições, de acordo com os professores entrevistados dificultam a formação docente, pois estes passam a maior parte do curso sem conhecer a realidade complexa da escola.

Diante desses fatos, os professores propõem uma relação maior entre essas instituições responsáveis pela formação profissional do professor. Eles mencionam a importância dos professores formadores visitarem mais a escola, e assim, ficarem mais informados sobre o que acontece no espaço escolar. E que não utilizem apenas esse espaço para suas pesquisas, que muitas vezes não retornam pra escola.

\section{5 - Considerações Finais}

Como dito anteriormente a pesquisa se encontra em andamento, mas diante do exposto podemos perceber que o professor da Educação Básica adquire ao longo de sua formação inicial e continuada saberes que são utilizados e mobilizados no cotidiano de suas aulas. E que esses saberes precisam ser considerados nas pesquisas sobre formação docente.

Com relação às políticas públicas para fortalecer a formação do professor, percebemos que tivemos avanços nos cursos de licenciatura com a criação das DCN, com aumento da carga horária dos Estágios Supervisionados, entre outros fatores positivos. Mas apesar da criação das políticas para aproximar universidade-escola, ainda percebemos um distanciamento entre essas instituições. Talvez um dos fatos pra que essa aproximação não ocorra, seja porque essas políticas estejam apenas no papel e, não estão sendo postas em prática efetivamente.

Torna-se cada vez mais necessário essa interação entre universidade-escola, teoria-prática para que tenhamos professores capazes de atuar diante da complexidade que envolve o espaço escolar, e assim, formarem cidadãos mais comprometidos com a sociedade.

\section{6 - Referências}

BRASIL, Ministério da Educação. Conselho Nacional de Educação. Parecer CNE/CP 009/2001: Diretrizes Curriculares Nacionais para a Formação de Professores da Educação Básica, em nível superior, curso de licenciatura, de graduação plena. Disponível em: <http:/ /portal.mec.gov.br/cne/index>. Acesso em: 27 mar. 2012.

Ministério da Educação. Conselho Nacional de Educação. Parecer CNE/CP 492/2001: Diretrizes Curriculares Nacionais dos cursos de Filosofia, História, Geografia, Serviço Social, Comunicação Social, Ciências Sociais, Letras, Biblioteconomia, Arquivologia e Museologia. Disponível em: <http:/ /portal.mec.gov.br/cne/index> . Acesso em: 27 mar.2012.

Conselho Nacional de Educação. Define as Diretrizes Curriculares Nacionais para a formação inicial em nível superior (cursos de licenciatura, cursos de formação pedagógica para graduados e cursos de segunda licenciatura) e para a formação continuada. Resolução CNE/CP n. 02/2015, de 1ํ de julho de 2015. Brasília, Diário Oficial [da] República Federativa do Brasil, seção 1, n. 124, p. 8-12, 02 de julho de 2015. Disponível em: <http:/ /portal.mec.gov.br/cne/index> . Acesso em: 07 mar.2016.

CACETE, N. H. Reforma educacional em questão: os Parâmetros Curriculares Nacionais para o ensino de Geografia e a formação de professores para a escola básica. In. ALBUQUERQUE, M. A. M; FERREIRA, J. A. de S. (Orgs.). Formação, Pesquisas e Práticas Docentes: Reformas Curriculares em

Para0nde!?, Porto Alegre, v.10, n.2, p.96-102, 2018. Edição Especial com artigos publicados originalmente na XII ENANPEGE http://seer.ufrgs.br/paraonde 
Questão. João Pessoa: Mídia, 2013, p. 47-58.

CAVALCANTI, L. de S. O Ensino de Geografia na Escola. Campinas - SP: Papirus, 2012, p. 208.

GATTI, B. Formação de professores e carreira: problemas e movimentos de renovação. Campinas, SP: Autores Associados, 2000, p. 119.

LEÃO, V. de P. Os cursos de Geografia e as Diretrizes Curriculares Nacionais para a formação de professores da educação básica. In. ALBUQUERQUE, M. A. M; FERREIRA, J. A. de S. (Orgs.). Formação, Pesquisas e Práticas Docentes: Reformas Curriculares em Questão. João Pessoa: Mídia, 2013, p. 15-45.

PIMENTA, S. G. Formação de professores - saberes da docência e identidade do professor. Nuances, vol. III, p. 5-14, set. 1997.

NÓVOA, A. Para uma formação de professores construída dentro da profissão. Revista Educación, n.350, set.-dez. 2007. Disponível em: http://www.revistaeducacion.mec.es/re350_09.html. Acesso em: 28 abr. 2017.

TARDIF, M. Saberes Docente e Formação Profissional. Petrópolis, RJ: Editora Vozes, 2014. p. 227-244.

ZEICHNER, K. M. Para além da divisão entre professor-pesquisador e pesquisador acadêmico. In: GERALDI, C. M. et al. (Orgs). Cartografias do Trabalho Docente: professor(a)-pesquisador(a). Campinas, SP: Mercado de Letras, 1998. p. 207-236. 